\title{
Comparison between Three Flaps for Reconstruction of Posttraumatic Soft Tissue Hand Defects
}

\author{
MOHAMMAD REDA AHMAD, M.D. \\ The Plastic and Reconstructive Surgery Unit, Faculty of Medicine, Zagazig University, Zagazig
}

\begin{abstract}
Introduction: Mutilating injuries of the hand that occur due to different types of trauma could produce soft tissue defects with, or without bone, tendons, and joint injuries. It is a challenge to reconstructive plastic surgeon.

Patients and Methods: Forty nine patients presented by hand soft tissue defects. The Patients were divided according to the procedure done into three groups: Posterior interosseous artery (PIA) flap (Group I), reversed radial forearm (RRF) flap (group II) and abdominal flap (group III).

Results: Post-operative DASH score and follow up period in abdominal flap operated group were significantly higher than that operated by PIA flap "group I" and "group II". Cosmetic evaluation of patients in group I was significantly higher than that of RRF flap, and abdominal flap. There was a postoperative significant improvement of the angle of first web space in comparison to preoperative angle in six cases operated for contracture of the first web space. The postoperative complications in PIA flap operated group were $21.05 \%$, and $27.78 \%$ in RRF flap operated group. In abdominal flap operated group $78.95 \%$ of cases showed complications.

In Conclusion: Reconstructive plastic surgeon should have the capability and plasticity in dealing with soft tissue defects of the hands, with best recruitment of the available local forearm flaps, and distant flaps. Each patient should be individually studied and well counseled before the choice of the proper reconstructive method.
\end{abstract}

Key Words: Soft tissue - Defect - Reconstruction - Flaps Hand.

\section{INTRODUCTION}

Moderate to severe soft tissue defects of the hand represent one of common events in daily scenario. These defects can expose important structures like bone, tendons, vessels, nerve, or even open joints [1]. Machinery injuries and road traffic injuries are the commonest causes [2]. These defects need a flap to prevent vital structures deterioration, to aid in faster healing, and to keep hand function $[3,4]$.
The methods of reconstruction should be versatile, applicable, reliable, associated with minimal donor site morbidity, with better recruitment of blood supply available. Surgeon's experience and preference are determinant of the choice of the reconstruction technique, with two eyes, one interested on functional restoration, and another looking for aesthetic appearance of the recipient and donor areas [5].

Three principle territory of arterial blood supply from the forearm to the hand are apparent, supplying different regions and tissues in the forearm. So the forearm is a rich site for fasciocutaenous perforator flaps [6,7].

Classically speaking, the arterial flow through the reversed radial forearm flap is dependent on the distal backflow from ulnar artery. The drainage of venous blood passes through venae commitants associating with the radial artery [8].

Reversed radial forearm flap (RRF flap), dependent on the reversed flow, reversed posterior interosseous artery (PIA) flap, and abdominal flap are options for reconstruction of different hand defects $[\mathbf{9 , 1 0 ]}$.

Initially, the reconstruction of the defects of the hands by abdominal flap was a valuable method of reconstruction, because of the simplicity, easiness, versatility, and no needs for a lot of expertise $[11,12]$.

The aim of this study is to evaluate the functional and aesthetic results of three models of flap reconstruction of the different soft tissue defects of the hands, including reversed flow radial forearm flap, posterior interossous artery based forearm flap, and abdominal flap. 


\section{PATIENTS AND METHODS}

\section{Patients:}

In the period from January 2012 to May 2016, Forty nine patients presented by hand soft tissue defects caused by occupational injuries (industrial) in 24 cases, 10 rood traffic accident patients, 5 Post burn, 4 post explosion, 3 domestic injuries, 2 post old trauma scarring, and post electric burn in one case.

Patients were divided according to the procedure done into three groups:

PIA flap group (Group I): 19 patients (16 males and 3 females), their age ranged from 10 to 42 years $(29.89 \pm 8.66)$, showed defect size ranged from $4 \times 7 \mathrm{~cm}$ to $12 \times 9 \mathrm{~cm}$; right hand was affected in 8 of them, and 11 on left hand. The soft tissue defects were in dorsum of the hand (12 cases), palmer aspect of the wrist ( 2 cases) thumb (one case), dorsum of the hand with the thenar eminence (one case), palmer aspect of the thumb (one case) and $1^{\text {st }}$ web space (one case).

RRF flap (Group II): 12 patients (10 males and 2 females), their age ranged from 8 to 56 years $(28.08 \pm 10.97)$, presented by defect size ranged from $3 \times 8 \mathrm{~cm}$ to $14 \times 20 \mathrm{~cm} ; 7$ of them on right hand and 5 on left hand. The soft tissue defects were in: the $1^{\text {st }}$ web space ( 3 cases), dorsum of the hand ( 2 cases), palm (3 cases), Palm with $1{ }^{\text {st }}$ web (one case), palmer aspect with lateral side of the hand (one case), Palmer and base of the thumb (one case) and Palmer with dorsum of the hand (one case).

Abdominal flap (Group III): 18 patients (17 males and 1 female), their age ranged from 12 to 40 years $(25.83 \pm 9.84)$, presented by defect size ranged from $4 \times 12 \mathrm{~cm}$ to $16 \times 10 \mathrm{~cm} ; 14$ of them on right hand and 4 on left hand. The soft tissue defects were in: Dorsum of the hand (9 cases), palmer aspect of the hand (4 cases), the $1^{\text {st }}$ web space (1 case), exposed metacarpals (one case), Exposed metacarpal after amputation ( 2 case), and Part of palmer and dorsal hand at the ulnar side (one case).

\section{Methods:}

This retrospective study design was approved by ethical committee of institutional review board (IRB) of Faculty of Medicine, Zagazig University. Written consents containing the details of operative and postoperative interventions with permission for pre and post-operative photography were taken from all patients included in this study.
Operative procedures:

I- PIA flap:

At the start of drawing of the flap, the upper limb of the patient was kept in elbow flexion $90^{\circ}$, and his wrist in neutral status. Then a straight line was drawn from tip of lateral epicondyle to the distal radio-ulnar junction. This line then divided into 3 thirds. The flap usually designed to be elevated to match the defects centered at the middle third. The hand Doppler can assist in demarcation of the course of the posterior interosseous artery, then application of a tourniquet is done to upper arm. Dealing with the soft tissue defect area by debridement and preparation is to be done meticulously. In dealing with the cases of first web space contracture, an incision to release this contracture from both dorsal side and palmer side is to deepen the web. After that, release the fascial contracture and muscle contracture to attain good web space [13].

The elevation of the flap starts by assuring of the presence of connection between anterior interosseous and posterior interosseous artery at the pivot point (about $2 \mathrm{~cm}$ proximal to radioulnar joint). Incision of the skin proximal to this point and careful detection of PIA arcade starts, then proximal elevation of the flap is continued with respect of the septum. After identification of the first sized septocutanous perforator of PIA, the pedicle was legated just proximal to this point. Elevation of the flap with the septum and vascular pedicle as one segment is adopted, then this flap is transposed to its final destination with incision to release bar of skin in between to avoid any kink or congestion. Closure of the donor site by split thickness skin graft is performed. Elevation and splinting of the arm for 7 days is to be ascertained. After that initial period of monitoring of the viability of the flap was done, then later regular follow up is to be done with physical therapy started on second week.

\section{II- RRF Flap:}

Clinical Allen test to assess the status of communication between ulnar and radial artery in the hand is essential step before radial forearm flap elevation. General anesthesia or regional supraclavicular block is to be used according to the need. A pneumatic tourniquet was applied to proximal arm as previous flap. According to the defect dimension and its distance from the expected pivot point $(2 \mathrm{~cm}$ from radial styloid process), the flap was designed centered on the course of the radial artery, with enough length from the designed island to the pivot point. Skin incision was done in a lazy $\mathrm{S}$ fashion, and then elevation of the island of the 
skin with the fascia, the pedicle for RRF flap was legated at the proximal part of forearm, with preservation of cutaneous nerves, then dissection of the flap from proximal side to distal. Another care should be exerted to avoid superficial radial nerve injury distally. The flap was transported to the defect site, then after grafting of the donor area.

\section{III- Abdominal flap:}

The general anesthesia was given to patients, then design of the flap according to the defect and position of upper limb during insetting of the flap. Optimal preparation of the recipient area was achieved, then elevation of the abdominal flap according to the plan, either through its thickness with further times of defattening, or through the plane between thin sub-dermal fat and remaining fatty layers just preserving subdermal vascular plexus. After being sure of the comfortable position of the upper limb, insetting of the flap was done by using Polyglyconic acid $3 / 0$ or $2 / 0$, and $4 / 0$ according to the status. The position of the flap was kept by elastoplast bandage. The flap was separated at $3^{\text {rd }}$ week.

All the patients of the three groups were scheduled for follow up and physical therapy according to the situations of the patients, and associated lesions. Assessment of the results was done by assessing the quick DASH questionnaire, then evaluating the cosmetic results according to thickness of the flap, matching of the color, and donor site status. From 10 degrees scale each parameter of the previous three was evaluated separately, then the mean of the three scores was the final step [14].

\section{Statistical analysis:}

Data were analyzed by Statistical Package of Social Science (SPSS), software version 22.0 (SPSS Inc., 2013). Continuous data were expressed as Mean $\pm S D$, while the nominal data were presented by the frequency and percentage. The one-way analysis of variance (ANOVA) is used to determine whether there are any significant differences between the means of three groups (PIA flap, RRF flap and abdominal flap). Least significance difference (LSD): It is one of the post hoc tests. It is used for multiple comparisons between every two groups. It was calculated at different probability values. $p$-value $<0.05$ considered significant.

\section{RESULTS}

Regarding the mean value of patient's age (years) among the three operated groups, no significant difference could be detected $(p>0.05)$. The flaps size in group III (abdominal flap) (128.94
$50.98 \mathrm{Cm}^{2}$ ) were significantly larger than that of the other groups; PIA flap "group I" (70.21 \pm 18.3 , $p<0.001)$ and RRF flap "group II" $(91.0 \pm 57.04$ $\mathrm{Cm}^{2}, p<0.05$ ), however, no significant difference could be detected between group I and group II regarding flap size $(p>0.05)$. The mean value of Post-operative DASH score in abdominal flap operated group "group III" (38.39 \pm 12.45$)$ was significantly higher than that operated by PIA flap "group I" $(18.17 \pm 9.90, p<0.001)$ and RRF flap "group II" (24.08 $\pm 12.59, p<0.01)$, however, no significant difference could be detected between group I and group II $(p>0.05)$ as regard postoperative DASH score. Concerning the cosmetic evaluation, While the mean value of group I (PIA flap) was significantly higher than that of RRF flap "group II $(6.42 \pm 0.90, p<0.001)$ and abdominal flap "group III" $(5.99 \pm 1.01, p<0.001)$, there was a non-significant difference could be detected between the PIA and RRF flaps $(p>0.05)$. The mean value of follow-up period was significantly longer in abdominal flap operated group (18.72 \pm 11.12 months) when compared to that of PIA flap $(9.68 \pm 4.00, p<0.001)$ and RRF flap operated group $(8.25 \pm 2.42, p<0.001)$, in addition the follow-up period showed non-significant deference between PIA flap and RRF flap operated groups $(p>0.05)$ (Table 1).

Regarding the six cases of first web space defect (one operated by PIA, four operated with RRF flap and one operated by abdominal flap), there was a postoperative significant improvement of the angle of first web space $(51.67 \pm 9.31)$ in comparison to preoperative angle $(7.5 \pm 2.74, p<0.001)$.

Concerning the donor sites closure, while the all cases of PIA flap (100\%) closed by Split thickness skin graft, 10 cases of RRF flap (83.33\%) closed by split thickness skin graft and the other 2 cases closed directly as the size of flaps were smaller. Furthermore, most of the cases of abdominal flaps (16 cases, $88.89 \%$ ) the donor sites were closed directly and only 2 cases $(11.11 \%)$ needed split thickness skin graft.

Regarding the postoperative complications, in PIA flap operated group $21.05 \%$ of cases showed complications (4 patients) there was a marginal flap loss in 2 cases, a scar at donor site in one case and a bulky flap in one case. In RRF flap operated group, $27.78 \%$ of cases showed complications (5 patients) two of them had Partial flap loss, two got bulky flap and one had a keloid scar. In abdominal flap operated group $78.95 \%$ of cases showed complications (15 patients), there was a bulky flap in eight cases, donor wound dehiscence in four cases and Partial flap loss in three cases. 
Table (1): Statistical analysis of age (years), flap size $\left(\mathrm{Cm}^{2}\right)$, postoperative DASH score, cosmetic evaluation score and followup period (month) between the three operated groups (PIA flap, RRF flap and abdominal flap).

\begin{tabular}{llccc}
\hline Parameters & Statistical & $\begin{array}{c}\text { PIA flap } \\
\text { (group I) }\end{array}$ & $\begin{array}{c}\text { RRF flap } \\
\text { (group II) }\end{array}$ & $\begin{array}{c}\text { Abdominal flap } \\
\text { (group III) }\end{array}$ \\
\hline Age (year) & Mean \pm SD & $29.89 \pm 8.66$ & $28.08 \pm 10.97$ & $25.83 \pm 9.84$ \\
& $p$-value & & $0.615^{\mathbf{a}}$ & $0.209^{\mathbf{a}}, 0.537 \mathbf{b}$ \\
Flap size $\left(\mathrm{cm}^{2}\right)$ & Mean \pm SD & $70.21 \pm 18.30$ & $91.0 \pm 57.04$ & $128.94 \pm 50.98$ \\
& $p$-value & & 0.199 & $<0.001^{\mathbf{a}}, 0.023^{\mathbf{b}}$ \\
MASH score & Mean \pm SD & $18.17 \pm 9.90$ & $24.08 \pm 12.59$ & $38.39 \pm 12.45$ \\
& $p$-value & & $0.17 \mathbf{a}$ & $<0.001^{\mathbf{a}}, 0.002^{\mathbf{b}}$ \\
Cosmetic evaluation & Mean \pm SD & $8.11 \pm 0.96$ & $6.42 \pm 0.90$ & $5.99 \pm 1.01$ \\
& $p$-value & & $<0.001^{\mathbf{a}}$ & $<0.001^{\mathbf{a}}, 0.24 \mathbf{b}$ \\
Follow-up & Mean \pm SD & $9.68 \pm 4.00$ & $8.25 \pm 2.42$ & $18.72 \pm 11.12$ \\
& $p$-value & & 0.59 & $<0.001^{\mathbf{a}},<0.001^{\mathbf{b}}$ \\
\hline
\end{tabular}

$\mathbf{a}=$ Versus group I. $\quad \mathrm{b}=$ Versus group II.

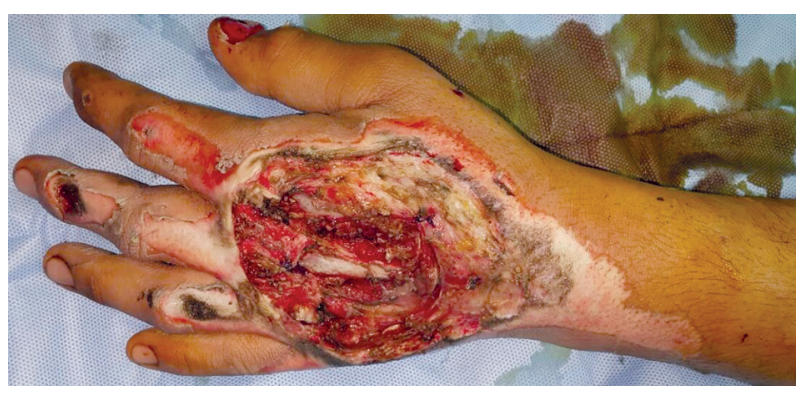

Fig. (1): Preoperative soft tissue defects at dorsum of the left hand.

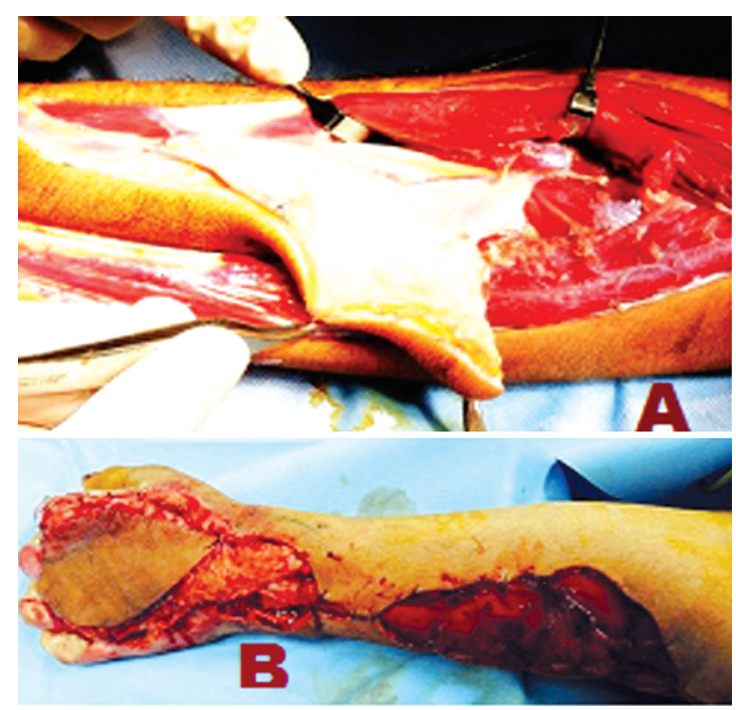

Fig. (2): Intraoperative dissections of the PIA flap to be sure of distal anastomosis (A), insetting of the PIA flap (B).

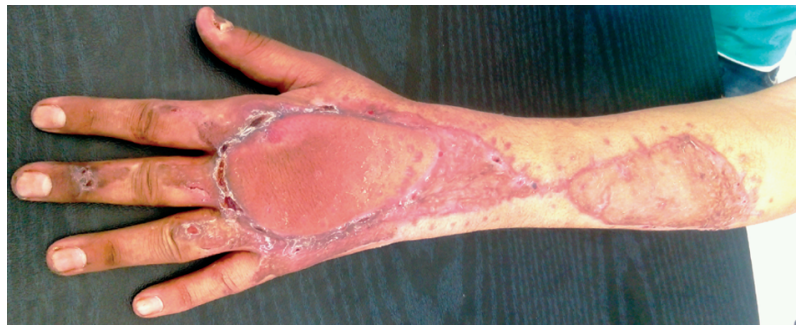

Fig. (3): Post-operative results after PIA flap for soft tissue defects in dorsum of hand.
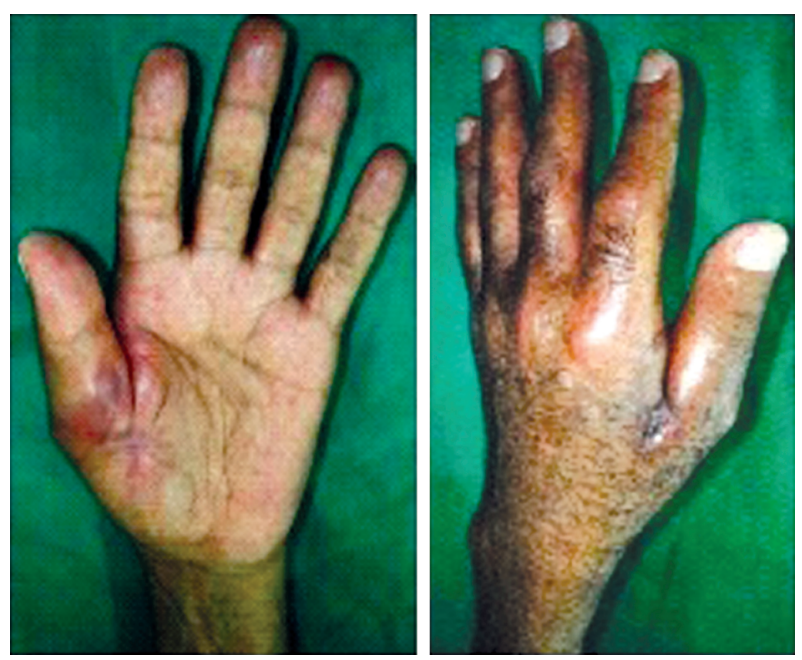

Fig. (4): Preoperative first web space contracture volar surface and dorsal view. 

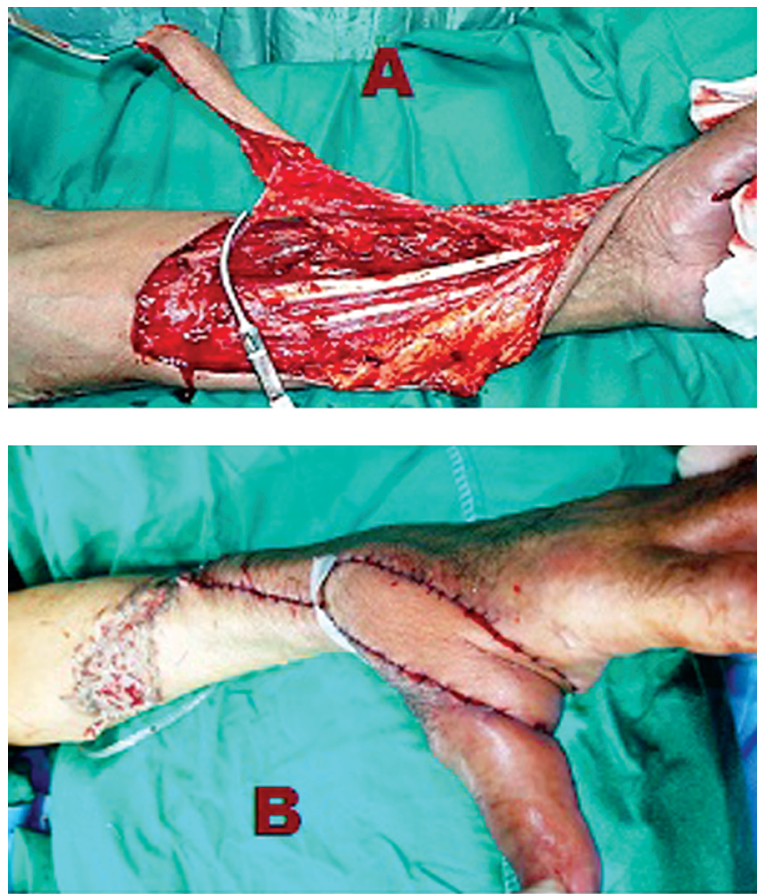

Fig. (5): Intraoperative dissection and flap elevation of RRF flap (A), insetting of RRF flap dorsal view (B).

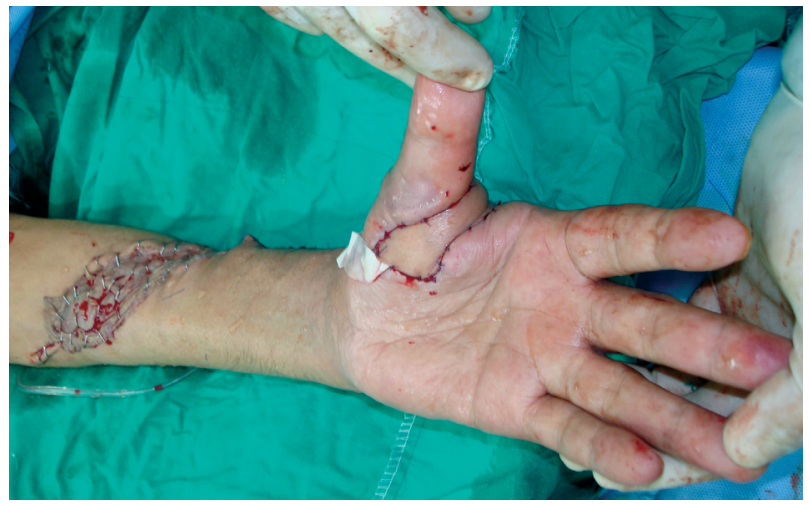

Fig. (6): Insetting of RRF flap volar view.

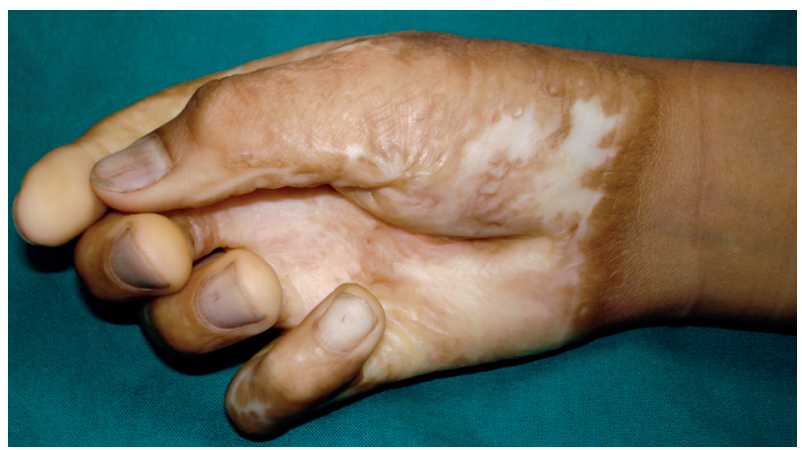

Fig. (7): Preoperative severe contracture post burn volar view.

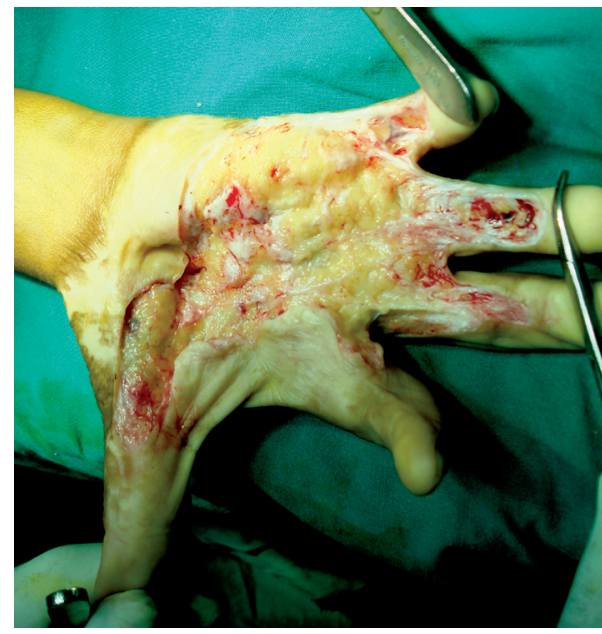

Fig. (8): Intra-operative severe contracture post burn after excision of the contracted skin.

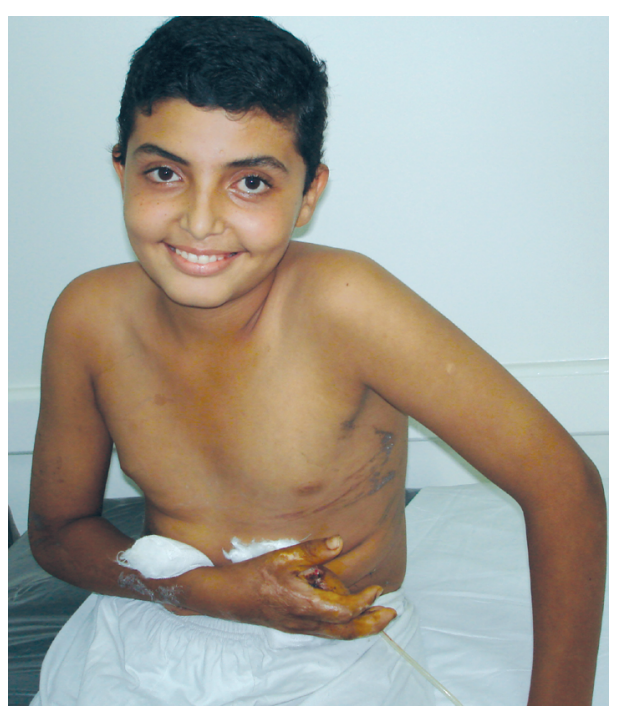

Fig. (9): Postoperative abdominal flap not separated yet.

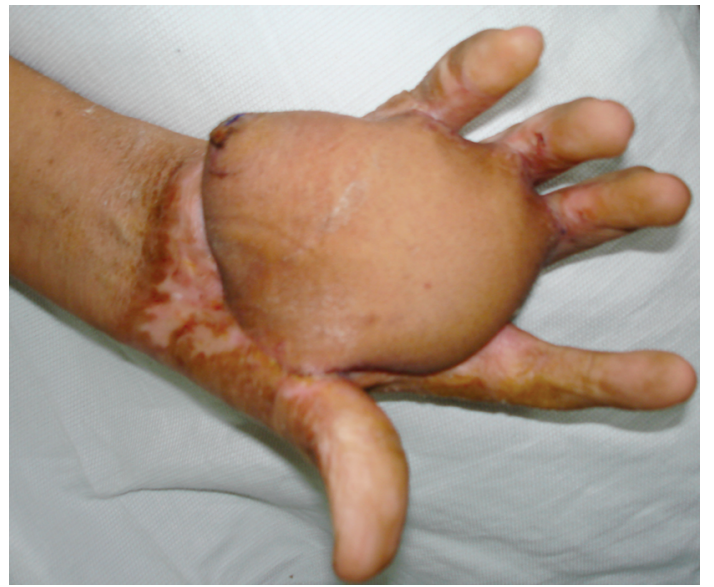

Fig. (10): Postoperative abdominal flap after separation. 


\section{DISCUSSION}

A considerable trauma to the hand can produce mutilating soft tissue defects, which may be associated with bone, tendons, and joints injuries [15]. These conditions represent challenges to reconstructive plastic surgeon. Several surgical techniques used to resurface skin defects of the hand [6].

The available reconstructive methods for soft tissue coverage of the hand are many, ranging from local, retrograde forearm flaps, distant flaps, and free flaps. The choice is usually dependent on local surrounding tissues and wound status, and general health of the patients [16].

As regard the merits of using free tissue transfer in soft tissue reconstruction of the hand are the freedom of size, site, and free flap insetting. In other way, free flaps have disadvantages like the need of a lot of resources needed, and necessity of experienced micro-surgeon [17]. In between local hand flaps, and free flaps, two groups are present. These two groups are reversed forearm flaps, and distant abdominal flap [18].

The flaps based on the reverse flow of blood in vascular arcades to supply forearm skin to be used in the reconstruction technique, represent a cosmetic, color and texture matched flaps with pliable thin skin, with early limb elevation, single stage reconstruction. Others advantages include, early feasibility of hand mobilization, and restricting the surgical trauma to ipsilateral limb [19]. This type of flaps includes, reversed radial forearm flap (RRFF), and posterior interoseous artery flap (PIAF) $[20,21]$.

RRF flap has a stable, effective, mostly hairless, potent blood flow, reliable, with no need of microsurgery; and a safe single stage reconstruction of soft tissue hand defects [22,23].

The similarity of the RRF flap as regard quality of skin to that of the hand especially the dorsum is an important factor in selecting this flap. Another factor is the versatility of this flap, as its highly reliable than a lot of distant flap and [15]. The dimension of the RRF flaps used in the present research ranged from $3 \times 8 \mathrm{~cm}$ to $14 \times 20 \mathrm{~cm}$; The mean value of Post-operative DASH score in RRF flap "group II" was favorable, $(24.08 \pm 12.59)$. The cosmetic score of the RRF flap was significantly better than that of abdominal flap, but less than that of PIA flap.

The cosmetic problem of the donor area and the sacrificing of the radial artery are two major disadvantages of the RRF flap reported by Ahn et al. [22] and Zhou et al. [24].

In many times, no harm occurred after this sacrifice of the radial artery; in other instances some cold intolerance may be happened. So in many schools, preserving both ulnar and radial artery is the role [25-27].

PIA flap was presented by Zancolli and Angrigiani in 1988. This flap based on the anastomosis between anterior interosseous artery and posterior interosseous artery. A lot of surgeons depend on this flap to avoid sacrificing one of main arteries of hand [29].

Another merit makes the PIA flap popular is perfect matching to the defects in dorsum of the hand and wrist, palmer aspects of the hand and wrist, and distal up to metacarpal in certain situations [30].

According to opinion of some authors, and after the widespread of PIA flap, the make use of RRF flap, free flaps, and abdominal flap were decreased [31].

The recommendation of using preoperative Duplex to be sure of anastomosis between anterior and posterior interosseous arteries is highly advised by some surgeons. This idea is not recommended by Costa in his work [32].

The dimensions of the PIA flap in literature are variable, certain studies declared a flap with $16 x$ $10 \mathrm{~cm}$, others presented a smaller dimensions (between $8 \times 5 \mathrm{~cm}$, and $3 \times 3 \mathrm{~cm})$. Buchler and Frey [33] made a use of flaps from $(9 \times 11 \mathrm{~cm}$, to $3 \times 3 \mathrm{~cm})$. Dap et al. [34] presented in their study a biggest flap was $15 \times 9 \mathrm{~cm}$. Costa's cases varied from $4 \times 5 \mathrm{~cm}$ to maximum $14 \times 9 \mathrm{~cm}[32,35]$. Lu et al. [36] had flaps up to $16 \times 10 \mathrm{~cm}$. In Balakrishnan's series the biggest PIA flaps were $21 \times 10 \mathrm{~cm}$ [37]. Another idea, that the dimension of the flap may be the whole skin on back of forearm [38]. In the present work, the flap dimension ranged from $4 \times 7 \mathrm{~cm}$ to $12 \times 9 \mathrm{~cm}$. The cosmetic appearance of PIA flap was significantly higher than that of both RRF flap and abdominal flap; no significant difference could be detected between the PIA and RRF flaps regarding cosmetic evaluation. So PIA flap was represented as a thin esthetic flap [39].

The drawbacks of the PIA flap are the variations in distal anastomosis between the two interosseous arteries, limited flap sizes, and restricted limit of reach of flap. Angrigiani presented one of 80 cases 
with no anastomosis distal [25], Büchler and Frey in two of 36 cases [33] and Panteado et al., in four of 70 cadaver specimens [40]. Lu et al. [36] described a case of flap failure from 90 cases, due to absence of distal anastomosis. I did not encountered this problem in this study, may be due to the fewer number of cases (19).

Two complications may occur from this flap radial nerve motor branches palsy, and possibility of venous congestion. In certain literatures, a $34 \%$ congestion and edema of the PIA flap may happen [9, 31,37]. Chen et al., [41] suggested to do distal venous anastomosis with intraoperative congestion Tahseen et al., had a reverse idea, as they did not encounter this problem in their cases [9]. As regard the postoperative complications in this series of patients were $21.05 \%$ in PIA flap operated group, in RRF flap operated group complications were $27.78 \%$ of cases. But in abdominal flap operated group $78.95 \%$ of cases showed complications (15 patients), so the PIA flap was the least in complications in comparison with other 2 groups.

Three sites in the anatomy of PIA flap can produce problems in flap elevation. The first one is the possibility of absence of distal anastomosis between anterior and posterior interosseous arteries [43]. The second is the middle part of posterior interosseous artery, which may be absent or very narrow. Some authors consider this part as a choke anastomosis between proximal one third and distal one third $[25,33]$. The third point is the origin of first septocutaneous perforator from the PIA [25].

The presence of an adequate first web space is essential for normal hand function of pinch, and grip [44,45].

First space contracture may occur after burn contracture or post trauma. This problem is very devastating [46]. Deepening and widening of the web space between thumb and index to restore thumb and hand function is essential. After these surgeries, soft tissue defects on the palmer and dorsal aspects and first web itself, resulting in a long and narrow tissue defect $[\mathbf{4 6 , 4 7 ]}$. The three types of flap surgery, RRF, abdominal, and PIA flaps can be used to resurface this first space after contracture release $[\mathbf{4 8 , 4 9 ]}$. In this study, six of cases presented with a first web space defect, after release of this contracture, there was a significant improvement of the angle of first web space.

One of the reconstructive methods of soft tissue defects in the hand and first web space is the random pattern abdominal flap that was very popular for long time. The drawbacks of this flap are two stage procedure, bulkiness and thickness of the flap necessitating defattening, and long period of immobilization during insetting of the flap [50].

The classic raising of the abdominal flap is through tissue planes to take most of the subcutaneous superficial fascia with the skin and subdermal plexus. With thin patient the resulting flap will be thin, but the problem with obese patients. In obese cases surgeon faces the challenge of taking a thick bulky flap or to raise the flap thin in the plane just preserving skin, subdermal plexus, and little fat under this plexus [51,52].

\section{In conclusion:}

In the deal with soft tissue defects of the hands, plastic reconstructive surgeon should have the ability to use all available flaps, with best understanding of the merits and drawbacks. Each patient should be individually studied and well counseled before the proper reconstructive method is chosen.

\section{REFERENCES}

1- Giessler G.A., Erdmann D. and Germann G.: Soft tissue coverage in devastating hand injuries. Hand Clin., 19: 63-67, 2003.

2- Bardsley A.F., Soutar D.S., Elliot D., et al.: Reducing mor-bidity in the radial forearm flap donor site. Plast. Reconstr. Surg., 86 (2): 287-294, 1990.

3- Chang S.M. and Hou C.L.: The development of the distally based radial forearm flap in hand reconstruction with preservation of the radial artery. Plast. Reconstr. Surg., 106 (4): 955-957, 2000.

4- Taghinia A.H., Carty M. and Upton J.: Fascial flaps for hand reconstruction. J. Hand Surg. Am., 35: 1351-135, 2010.

5- Flugel A., Kehrer A., Heitmann C., Germann G. and Sauerbier M.: Coverage of soft tissue defects of the hand with free fascial flaps. Microsur., 25: 47-53, 2005.

6- Liu D.X., Wang H., Li X.D. and Du S.X.: Three kinds of forearm flaps for hand skin defects: Experience of 65 cases. Arch. Orthop. Trauma Surg., 131: 675-80, 2011.

7- Acharya A.M. and Bhat A.K.: The Reverse Posterior Interosseous Artery Flap: Technical Considerations in Raising an Easier and More Reliable Flap. J. Hand Surg. (ASSH), 37 (3): 575-582, 2012.

8- Kaufman M.R. and Jones N.F.: The reverse radial forearm flap for soft tissue reconstruction of the wrist and hand. Tech Hand Up Extrem Surg., 9: 47-51, 2005.

9- Tahseen A., Cheem A., Lakshman S., Cheema M.A. and Durran S.F.I.: Reverse-Flow Posterior Interosseous Flap A Review of 68 Cases. HAND, 2: 112-116. DOI 10.1007/ s11552-007-9031-9, 2007.

10- El-Sabbagh, A.H., Zeina, A.A.EM., Khalil, A.A.EG., et al.: Reversed radial forearm flap: An ad hoc flap for hand reconstruction. Eur. J. Plast. Surg., 35: 1, 2012. doi: 10.1007/s00238-011-0623-9. 
11- Yilmaz S., Saydam M., Seven E. and Ercocen A.R.: Paraumbilical perforator-based pedicled abdominal flap for extensive soft-tissue deficiencies of the forearm and hand. Ann. Plast. Surg., 54: 565, 2005.

12- Sabapathy S.R., Venkatramani H. and Playa P.M.: The use of pedicled abdominal flaps for coverage of acute bilateral circumferential degloving injuries of the hand. Trauma Case Reports, 1: 25-31, 2015.

13- Caroli A., Adani R., Scagni R. and Marcialis M.: Skin flap in first web retraction. Tech. Hand Upper Extrem Surg., 3: 197-202, 1999

14- Del Pinal F., Garcia-Bernal F.J. and Delgado J.: Is posttraumatic first web contracture avoid able? Prophylactic guideline s and treatment-oriented classification. Plast. Reconstr. Surg., 113: 1855-1860, 2004.

15- Jones N.F., Jarrahy R. and Kaufman M.R.: Pedicled and free radial forearm flaps for reconstruction of the elbow, wrist, and hand. Plast. Reconstr. Surg., 121 (3): 887-898, 2008.

16- Holzle F., Kesting M.R., Nolte D., et al.: Reversible ischaemia after raising a radial forearm flap with ulceration of three fingers in a cigarette smoker. Br. J. Oral Maxillofac. Surg., 44 (1): 57-59, 2006.

17- Varley I., Carter L.M., Wales C.J., et al.: Ischaemia of the hand after harvest of a radial forearm flap. Br. J. Oral Maxillofac. Surg., 46 (5): 403-405, 2008.

18- Manabe S., Tabuchi N., Toyama M., et al.: Measurement of ulnar flow is helpful in predicting ischemia after radial artery harvest. Thorac. Cardiovasc. Surg., 50 (6): 325328, 2002.

19- Heller F., Wei W. and Wei F.C.: Chronic arterial insufficiency of the hand with fingertip necrosis 1 year after harvesting a radial forearm free flap. Plast. Reconstr. Surg., 114 (3): 728-731, 2004.

20- Roberto A., Luigi T. and Ignazio M.: Hand reconstruction using the thin anterolatera 1 thigh flap. Plast. Reconstr. Surg., 116: 467-473, 2005.

21- Roberto A., Luigi T., Ignazio M. and Umberto F.: First web space reconstruction by the anterolateral thigh flap. J. Hand Surg., 31A: 640-645, 2006.

22- Ahn H.C., Choi M.S., Hwang W.J. and Sung K.Y.: The transverse radial artery forearm flap. Plast Reconstr Surg., 119: 2153-2160, 2007.

23- Akyürek M., Safak T. and Kecik A.: Oblique radial forearm reverse-flow flap. J. Reconstr. Microsurg., 19: 3-6, 2003.

24- Zhou L.R., Li J. and Wang W.: Microsurgical repair of skin-degloving injury of whole hand or foot. Zhongguo Xiu Fu Chong Jian Wai Ke Za Zhi, 17: 321, 2003.

25- Angrigiani C., Grilli D., Dominikow D. and Zancolli E.A.: Posterior interosseous reverse forearm flap: Experience with 80 consecutive cases. Plast. Reconstr. Surg., 92 (2): 285-93, 1993.

26- Suominen S., Asko-Seljavaara S. and Attovuo J.: Thermography and color doppler ultras onography of hands after radial forearm flap elevation. Presented at the $5^{\text {th }}$ Annual Meeting of the European Association of Plastic Surgeons, May 14, Geneva, p95, 1994.

27- Fang Q.G., Shi S., Zhang X., Li Z.N., Liu F.Y. and Sun C.F.: Upper extremity morbidity after radial forearm flap harvest: A prospective study. J. Int. Med. Res., 42: 231235,2014

28- Zancolli E.A. and Angrigiani C.: Posterior interosseous island forearm flap. J. Hand Surg. (Br.), 13: 130, 1988.

29- Gavaskar A.S.: Posterior Interosseous Artery Flap for Resurfacing Posttraum atic Soft Tissue Defect s of the Hand. HAND, 5: 397-402, 2010.

30- Brunelli F., Valenti P., Dumontier C., Panciera P. and Gilbert A.: The Posterior Interosseous Reverse Flap: Experience With 11 Flaps. Ann. Plast. Surgery, 47: 25$30,2001$.

31- Fujiwara M., Kawakatsu M., Yoshida Y. and Sumiya A.: Modified posterior interosseous flap in hand reconstruction. Tech Hand Up Extrem Surg., 7 (3): 102-109, 2003.

32- Costa H., Gracia M.L., Vranchx J., et al.: The posterior interosseous flap: A review of 81 clinical cases and 100 anatomical dissections-assessment of its indications in reconstruction of hand defects. Br. J. Plast. Surg., 54 (1): 28-33, 2001.

33- Büchler U. and Frey H.: Retrograde posterior interosseous flap. J. Hand Surg., 16 A: 283-292, 1991.

34- Dap F., Dautel G., Voche P., Thomas C., Merle M.: The posterior interosseous flap in primary repair of hand injuries. J Hand Surg 18 B:437-445, 1993.

35- Costa H., Comba S., Martins A., Rodrigues J., Reis J. and Amarante J.: Further experience with the posterior interosseous flap. Br. J. Plast. Surg., 44: 449-455, 1991.

36- Lu L.J., Gong X., Liu Z.G. and Zhang Z.X.: Antebrachial reverse island flap with pedicle of posterior interosseous artery: A report of 90 cases. Br. J. Plast. Surg., 57: 64552, 2004.

37- Balakrishnan G., Kumar B.S. and Hussain S.A.: Reverseflow posterior interosseous artery flap revisited. Plast. Reconstr. Surg., 111 (7): 2364-2369, 2003.

38- Mazzer N., Barbieri C.H. and Cortez M.: The posterior interosseous forearm island flap for skin defects in the hand and elbow. A prospective study of 51 cases. J. Hand Surg. (Br.), 21 (2): 237-43, 1996.

39- Heitmann C., Felmerer G. and Ingianni G.: The versatile uses of the posterior interosseous forearm flap. Eur. J. Plast. Surg., 22: 357-61, 1999.

40- Penteado C.V., Masquelet A.C. and Chevrel J.P.: The anatomic basis of the fascio-cutaneous flap of the poster ior interosseous artery. Surg. Radiol. Anat., 8: 209e15, 1986.

41- Chen H.C., Cheng M.H., Schneeberger A.G., Cheng T.J., Wei F.C. and Tang Y.B.: Posterior interosseous flap and its variations for coverage of hand wounds. J. Trauma, 45: 570-4, 1998.

42- Shibata M., Iwabuchi Y., Kubota S. and Matsuzaki H.: Comparison of free and reversed pedicled posterior interosseous cutaneous flaps. Plast. Reconstr. Surg., 99: 791-802, 1997.

43- Dadalt L.G., Ulson H.J.R. and Penteado C.V.: Absence of the anastomosis between the anterior and posterior interosseous arteries in a posterior interosseous flap: A case report. J. Hand Surg. [Am.], 19: 22-25, 1994 
44- Prakash V. and Mishra A.: Management of adduction contracture of the thumb with a prefabricated radial fascial flap. Plast. Reconstr. Surg., 114: 1681-1682, 2004.

45- Gülgönen A. and Güdemez E.: Reconstruction of the first web space in symbrachydacty ly using the reverse radial forearm flap. J. Hand Surg., 32A: 162-167, 2007.

46- Miyawaki T., Masuzawa G., Hirakawa M. and Kurihara K.: Bone-lengthening or symbrachydactyly of the hand with the technique of callus distraction. J. Bone Joing Surg., 84A: 986-991, 2002.

47- Rider M.A., Grindel S.I., Tonkin M.A. and Wood V.E.: An experience of the Snow-Littler procedure. J. Hand Surg., 25B: 376-381, 2000.

48- Horacio C., Armindo P. and Horacio Z.: The posterior interosseous flap a prime technique in hand reconstruction.
The experience of 100 anatomical dissections and 102 clinic cases. JPRAS, 60: 740-747, 2007.

49- Vinita P., Sanjay M. and Roshani R.: Posterior interosseous artery flap, fasciosubutaneous pedicle technique: A study of 25 cases. JPRAS, 60: 1331-1337, 2007.

50- Lin W., Zheng T. and Wang Q.: Study on the effect of pedicle skin flap of subdermal vascular plexus on repairing the hand injury. Zhongguo Xiu Fu Chong Jian Wai Ke Za Zhi, 19 (7): 528, 2005.

51- Forli A., Voulliaume D., Comparin J.P., Papalia I. and Foyatier J.L.: The abdominal flap-graft for coverage of soft tissue defects of the dorsum of hand and fingers in burn patients. Six cases reports. Ann. Chir. Plast. Esthet., 50: 146-53, 2005.

52- Ali A., Farag M. and Safe K.: Reconstruction of Hand and Forearm Defects by Abdominal Thin Skin Flaps Egypt, J. Plast. Reconstr. Surg., 31 (2): 181-185, 2007. 